EDITORIAL

\title{
Genotyping arrays, population genetic studies and clinical implications
}

(c) The Author(s), under exclusive licence to European Society of Human Genetics 2021

European Journal of Human Genetics (2021) 29:1591-1592; https://doi.org/ 10.1038/s41431-021-00979-7

Studying genomics at a population level is accepted to be vital both to understanding human variation, and the cause of human disease. Genotyping arrays are crucial tools for such studies. In this issue, Verlouw et al. compare the properties of 28 different genotyping arrays [1]. Not all arrays are created equal and some are better suited to different studies with different research questions. Such technology enabled Mattingsdal to study the genetic architecture of Norway for the first time [2]. They trace routes of immigration into Norway and provide evidence that diversification of genomic background in the South of the country is due to geographic isolation and restricted gene flow. This has implications for variant interpretation in clinical contexts, since the frequency and type of population variants will differ due to geographic considerations.

Variant classification not only helps diagnose human disease, but can define prognosis and management. Matsumoto et al. systematically review the literature to identify clinical correlates of different genetic variants in FLCN [3]. FLCN variants are associated with Birt-Hogg-Dube syndrome; which can present with skin lesions, renal carcinoma and pneumothorax. Data are presented to suggest that certain FLCN variants may cause pneumothorax but not other clinical features. This has important implications for clinical screening and follow up of these individuals.

The fetal phenotypes of genetic disease are being identified through prenatal genomic testing. In a single family, a COL4A2 variant was shown to segregate with hemiplegic cerebral palsy in a parent and prenatal intra-cerebral haemorrhage [4]. This underscores the clinical variability associated with COL4A2 with important implications for genetic counselling. Another example of clinical variability is provided by Haag et al. [5]. Heterozygous WDR11 variants are associated with hypogonadotrophic hypogonadism. In this issue, patients with bi-allelic WDR11 variants and a neurodevelopmental disorder are described. Ascertainment bias can also cloud our view of genotype-phenotype correlation [6]. Initially TAB2 variants were associated with congenital heart disease and cardiomyopathy. Engwerda et al. describe a larger cohort of individuals with TAB2 variants, some ascertained in a 'genotype-first' manner [7]. They confirm a syndromal phenotype with non-cardiac manifestations.

Neurofibromatosis is one of the more common 'rare diseases', and clinically well recognised. However, there is still an unmet need for treatment. The treatment priorities of stakeholders were identified in a Delphi study [8]. Malignant peripheral nerve sheath tumours and glioma were identified as treatment priorities for research.
Implementation science concerns itself with the study of how to move scientific and clinical advances into clinical practice. O'Shea et al. use an implementation science approach to investigate barriers to mainstreaming genetic testing for cancer in Australian Oncology clinics [9]. They identify a perceived lack of knowledge and confidence to discuss and consent for such testing as a barrier to implementation. The preferences of patients and families should also be taken account of when implementing and developing genetic services. This Australian study describes preferences towards rapid genome sequencing for critically ill children.

\section{Alisdair McNeill ${ }^{1,2}$ \\ ${ }^{1}$ Department of Neuroscience, The University of Sheffield, Sheffield, UK. ${ }^{2}$ Sheffield Clinical Genetics Department, Sheffield Children's Hospital NHS Foundation Trust, Sheffield, UK. 凶email: a.moneill@sheffield.ac.uk}

\section{REFERENCES}

1. Verlouw JAM, Clemens E, de Vries JH, Zolk O, Verkerk AJMH, am ZehnhoffDinnesen A, et al. A comparison of genotyping arrays. Eur J Hum Genet. 2021. https://doi.org/10.1038/s41431-021-00917-7.

2. Mattingsdal M, Ebenesersdóttir SS, Moore KHS, Andreassen OA, Hansen TF, Werge T, et al. The genetic structure of Norway. Eur J Hum Genet. 2021. https:// doi.org/10.1038/s41431-021-00899-6.

3. Matsumoto K, Lim D, Pharoah PD, Maher ER, Marciniak SJ. A systematic review assessing the existence of pneumothorax-only variants of FLCN. Implications for lifelong surveillance of renal tumours. Eur J Hum Genet. 2021. https://doi.org/ 10.1038/s41431-021-00921-x.

4. Hausman-Kedem M, Ben-Sira L, Kidron D, Ben-Shachar S, Straussberg R, Marom D, et al. Deletion in COL4A2 is associated with a three-generation variable phenotype: from fetal to adult manifestations. Eur J Hum Genet. 2021. https://doi.org/ 10.1038/s41431-021-00880-3.

5. Haag N, Tan E-C, Begemann M, Buschmann L, Kraft F, Holschbach P, et al. Biallelic loss-of-function variants in WDR11 are associated with microcephaly and intellectual disability. Eur J Hum Genet. 2021. https://doi.org/10.1038/s41431-02100943-5.

6. McNeill A, lovino E, Mansard L, Vache C, Baux D, Bedoukian E, et al. SLC12A2 variants cause a neurodevelopmental disorder or cochleovestibular defect. Brain. 2020;143:2380-7.

7. Engwerda A, Leenders EKSM, Frentz B, Terhal PA, Löhner $K$, de Vries BBA, et al. TAB2 deletions and variants cause a highly recognisable syndrome with mitral valve disease, cardiomyopathy, short stature and hypermobility. Eur J Hum Genet. 2021. https://doi.org/10.1038/s41431-021-00948-0.

8. Dhaenens BAE, Ferner RE, Bakker A, Nievo M, Evans DG, Wolkenstein P, et al. Identifying challenges in neurofibromatosis: a modified Delphi procedure. Eur J Hum Genet. 2021. https://doi.org/10.1038/s41431-021-00892-z.

9. O'Shea R, Rankin NM, Kentwell M, Gleeson M, Tucker KM, Hampel $\mathrm{H}$, et al. Stakeholders' views of integrating universal tumour screening and genetic testing for colorectal and endometrial cancer into routine oncology. Eur J Hum Genet. 2021. https://doi.org/10.1038/s41431-021-00871-4. 


\section{COMPETING INTERESTS}

AM is Editor in Chief of the European Journal of Human Genetics.

\section{ADDITIONAL INFORMATION}

Correspondence and requests for materials should be addressed to Alisdair MCNeill.
Reprints and permission information is available at http://www.nature.com/ reprints

Publisher's note Springer Nature remains neutral with regard to jurisdictional claims in published maps and institutional affiliations. 